\title{
Seminar and Project Manager and Resourceful Trainer(SMART)
}

\author{
Miss. Surya J. Khivsara, Miss. Shruti B.Chhapanimohan \\ B.E.(Scholar),P. R. Pote Engineering \& Technology,Amravati(MH) \\ B.E.(Scholar),P. R. Pote Engineering\& Technology,Amravati(MH)
}

\begin{abstract}
This paper presents an approach to eradicate all of the confusion which surrounds anyone while preparing for the project and seminar. Also it aims in helping the institution to manage the previous batch's seminars and project. Seminar and project activity mainly deals with effective data searching and keeping pace with emerging technologies. This paper focuses the concepts like keeping data at one place, providing guidance related to Projects and seminars. This paper can represent an application that can be used by anyone for solving queries related to project and seminar.
\end{abstract}

\section{Introduction:}

TECHNOLOGY-the building block of engineering rejuvenates every minute today and engineers are expected to keep a pace with these flourishing technologies. In this run, we engineers design projects and deliver seminar during our engineering courses. Lectures and guides instruct the student regarding the quality level and expectations related seminars and projects. Since project and seminar forms the most important part of engineering courses, this tedious task becomes vital too .This project aims in eradicating the instructor's workload by providing every instruction digitally. Students on the other hand strive hard to meet the expectations take help of internet .But internet surfing also becomes tedious as nothing is available under one roof. Data collection become s complicated and time consuming too. This project aims in making all the material available under roof and thus save student time. College has a tough job of maintaining record and collection of the projects and seminars which were done by the previous batches and not expected to be repeated or those which demand some modifications for better implementations. This projects aims in providing a provision for college to maintain this record. Basically, this project arises with an idea to develop departmental offline hubs which assist both the lectures and student for the project and seminar activity.

\section{Literature Review}

Various sites provide solution for the problems related to Seminars and Projects. Project Ideas is one of the site that forms an online hub, but one need to pay for any of the service you try to get. A4academics provides you place to hold your Projects and seminars and their ratings. Pantech solution provides you list of projects and seminars on various technologies. Techforum $4 u$ informs one about the new emerging technologies.

\section{Proposed methods:}

This project consists of following facilities;

i. A platform to keep all the presented seminars and projects at one place with all their pros and cons.

ii. A platform where one can search each and every information related to projects and seminars,

iii. A platform where you can search for new emerging technologies.

iv. A platform where you can seek for guidance related to your project and seminar.

The basic facilities available in the project can be seen in the figure given below. It enlists all the options which are encountered when anyone opens this application. It consists of following sections:

1. History

2. Project

3. Seminar

4. Upload

5. About us 


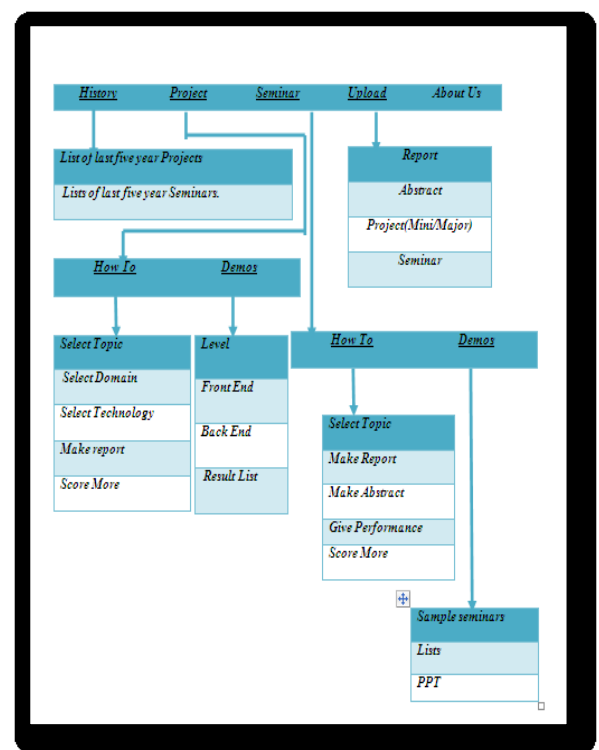

Fig: Facilities Available

Module 1. : History

History module consists of last five year projects and seminars depending upon the technologies. The admin have rights to modify the contents of this module. It will help students to keep track of already presented seminars and projects, so there is no scope of repetitions of seminars and projects. The following figure shows the result when somebody looks for the projects already done along with the year in which they are done.

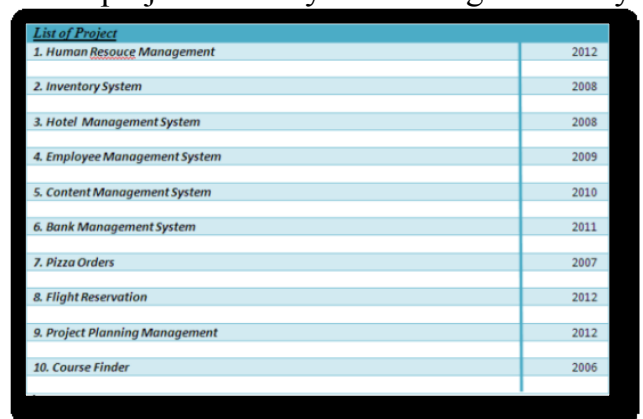

Fig: History result search

Module 2: Project

Project module consists of two sections:

- How to

- Demos

1. The How two section will guide students for selection of topics, domain and technologies. This will also guide the students how to make the report. Also, it would contain the marking scheme, thus will guide the students to score more. The following figure shows the result when somebody wants to know how to select project technology.

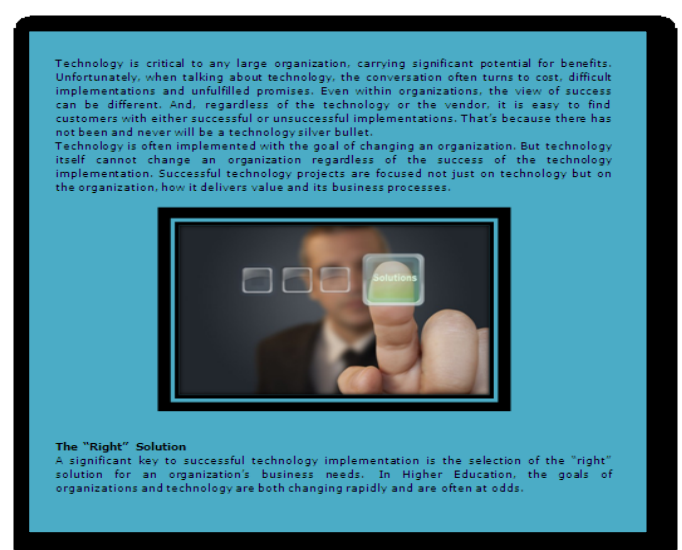

Fig: Result-How to select project technology 
2. The Demos section will be comprising of practical implementation of the technologies into projects along with downloading facility. User can search the projects on the grounds of the Front end, Back end and Level of the Projects(Mini or Major).After the desired validation is entered the user would be provided with the list of the projects with the entered validation. The following figure shows list of project having java as front end.

Module 3: Seminar

\begin{tabular}{|l|}
\hline $\begin{array}{l}\text { List of Projects having J.AVA as Front End } \\
\text { 1. Prisoner Face Detecting System a Java Project }\end{array}$ \\
\hline 2.Typing Patterns a Java Project \\
\hline 3.Harmful Mail Scanning a Java Project \\
\hline 4.Online Magazinea Java Project \\
\hline 5.Energy Billing System a Java Project \\
\hline \\
\hline 6.Bus Scheduling and Booking System a Java Project \\
\hline
\end{tabular}

Fig: Result Project lists with java front end

Seminars module also consist of two sections:

- How to

- Demos

1. How To section will be for the guidance. Guidance about how to select topic, how to make report, how to make abstract, how to give presentation. It would also consists of marking scheme, thus helping students to score more. The following figure shows search result for how to make seminar reports.

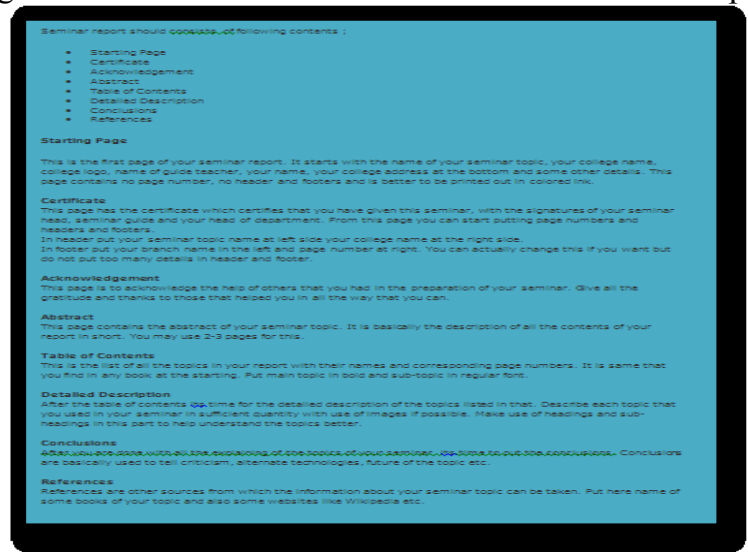

Fig: Result-How to make report

2. Demos will provide you lists and sample ppts. The following figure shows one such search result.

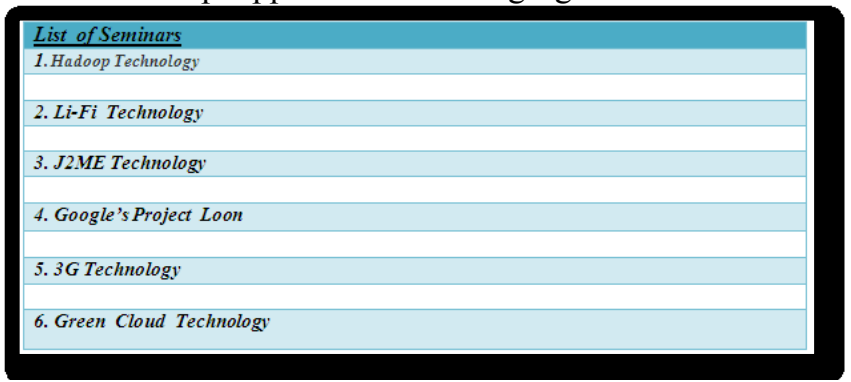

Fig: Result-lists of seminars

Module 4: Upload

With time, technology will change, there is no doubt in it, because every technology has one prominent feature i.e., it CHANGES. Now, the role of Admin comes into play. This section will be for the admin to add or delete projects, seminars, reports etc. according to the need and changes in technologies with time. An admin may insert Report, Abstract, Project (Mini/Major), Seminar (PPT).Thus; there is a provision to update the application periodically, for better usage. The following figure shows the authentication window for the admin of the project. 


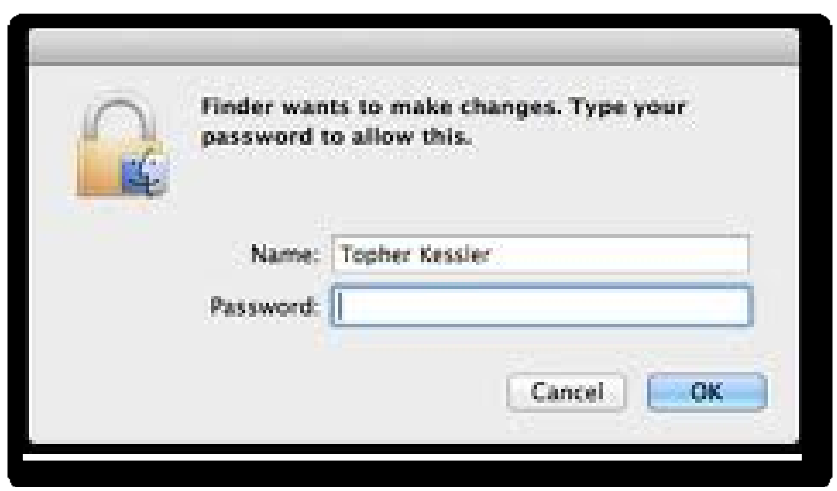

Fig-Authentication window for admin

\section{Conclusion:}

This project aims to be an asset for the college. It aims to become a complete reference for project and seminars. This project when develop will become a offline hub which will guide the students for every detail right from the selection of topic to the readymade projects for guidance. The SMART Application aims in helping college to effectively maintain the quality projects developed by the previous batches. This project will store the projects as per the database permits. All in all this SMART Application is a smart way to dealing with projects and seminar-all in one place.

\section{Future Scope}

There can be a provision made where the user can access the facilities online also.

\section{References}

[1]. A K Munns and B F Bjeirmi, "The role of project management in achieving project success", International Journal of Project Management Vol. 14, No. 2, pp. 81-87, 1996 (C) 1996 Elsevier Science Ltd and IPMA Printed in Great Britain 0263-7863/96

[2]. M.R. Martínez-Torres, S.L. Toral, F. Barrero, F. Cortés, (2010) "The role of Internet in the development of future software projects", Internet Research, Vol. 20 Iss: 1, pp.72-86

[3]. Petter Gottschalk, Jan Terje Karlsen, (2005) "A comparison of leadership roles in internal IT projects versus outsourcing projects", Industrial Management \& Data Systems, Vol. 105 Iss: 9, pp.1137 - 1149

[4]. Sharon Markless and David Streatfield "Information Management Associates "The Library and Information Commission 2000 Grant Number: LIC/RE/001 ISBN 0-9538432-2-X ISSN 1466-2949E

[5]. Christina M.Finneran,"Flow in computer mediated environments: Promises and challenges", Communication of the association for the Information system(volume 15,2005),82-101

[6]. Neil Selwn," Faceworking: exploring studentds education related use of facebook” DOI 101080/17439880902923622

[7]. Kathleen M. Eisenhardt, "Building theories from case study research" ,Standford California-94305 